\title{
Is blood transfusion harmful in patients with acute coronary syndromes?
}

Rao SV, Jollis JG, Harrington RA, Granger CB, Newby LK, Armstrong PW, et al. Relationship of blood transfusion and clinical outcomes in patients with acute coronary syndromes. JAMA 2004;292 (13):1555-62.

Background: There is uncertainty regarding the benefit of blood transfusions in anemic patients with acute coronary syndromes.

Design: This observational study analyzed clinical outcomes of 24112 patients who had previously participated in 3 large multicentre randomized clinical trials. Each of the 3 trials had randomly assigned patients with acute coronary syndromes to receive different anticoagulation or antiplatelet therapies. The authors examined the association between transfusion and the primary outcome of 30-day mortality and the secondary composite outcome of 30-day mortality or myocardial infarction.

Results: Of the 24112 patients, $2401(10.0 \%)$ received a blood transfusion. Compared with patients who did not receive a transfusion, those who did were more likely to be older, female, $\therefore$ black, have been treated at a $\exists$ hospital in the United States, have more comorbidities at presentation and have a lower baseline and nadir hematocrit. The authors found that patients who received blood had worse outcomes than those who did not receive blood (Table 1) and that the predicted probability of death within 30 days was most pronounced among transfused patients with a nadir hematocrit greater than $25 \%$.

Commentary: The authors of this study found that blood transfusion was associated with an increased risk of death within 30 days among patients with acute coronary syndromes and that the risk was most pronounced when transfusions were administered to patients with a hematocrit greater than $25 \%$.

The largest randomized clinical trial of blood transfusion in critically ill patients concluded that a restrictive transfusion strategy was at least as good as, and possibly superior to, a liberal transfusion strategy. ${ }^{1}$ In a subgroup analysis of patients with cardiac disease, there were no significant differences in clinical outcomes. ${ }^{1}$ However, in a subsequent observational study involving older patients admitted to hospital with myocardial infarction, $\mathrm{Wu}$ and colleagues ${ }^{2}$ reported a lower 30 day mortality among patients who received a transfusion and had an admission hematocrit of less than $33 \%$ than among

Table 1: Outcomes of patients with acute coronary syndromes who did and did not receive blood transfusion

\begin{tabular}{|c|c|c|c|c|}
\hline \multirow[b]{2}{*}{ Outcome } & \multicolumn{2}{|c|}{ Group; no. (\%) of patients } & \multirow[b]{2}{*}{$p$ value } & \multirow[b]{2}{*}{$\begin{array}{l}\text { Hazard ratio } \\
(95 \% \mathrm{Cl})^{*}\end{array}$} \\
\hline & $\begin{array}{l}\text { Transfusion } \\
n=2401\end{array}$ & $\begin{array}{l}\text { No transfusion } \\
n=21711\end{array}$ & & \\
\hline 30-day mortality & $192 \quad(8.0)$ & $669 \quad(3.1)$ & $<0.001$ & $3.94(3.26-4.75)$ \\
\hline MI & $604(25.2)$ & $1771 \quad(8.2)$ & $<0.001$ & NR \\
\hline $\begin{array}{l}\text { Composite of 30-day } \\
\text { mortality or MI }\end{array}$ & $702(29.2)$ & $2176(10.0)$ & $<0.001$ & $2.92(2.55-3.35)$ \\
\hline
\end{tabular}

Note: $\mathrm{Cl}=$ confidence interval, $\mathrm{MI}=$ myocardial infarction, $\mathrm{NR}=$ not reported.

*Adjusted for baseline charactertistics, bleeding and transfusion propensity, and nadir hematocrit.

those who received a transfusion and had a higher hematocrit. Both the study by $\mathrm{Wu}$ and colleagues and the current study by Rao and colleagues are limited by their observational nature, an inability to measure and adjust for all potential confounding variables and effect modifiers, and an inability to determine a causal relation between blood transfusion and clinical outcomes in patients with acute coronary syndromes.

Practice implications: The current evidence suggests that blood transfusions are unlikely to be beneficial when the hemoglobin concentration exceeds $100 \mathrm{~g} / \mathrm{L}$ (hematocrit > 30\%) in the absence of active blood loss. However, the benefits of transfusion may exceed the risks when the hemoglobin concentration falls to $70 \mathrm{~g} / \mathrm{L}$ (hematocrit $<21 \%$ ). Controversy remains for transfusion between these hemoglobin levels. A randomized clinical trial is needed to help elucidate which patients with acute coronary syndromes should receive blood transfusions and to what extent.

\section{Adel Al-Sarraf}

Department of Medicine

Robert A. Fowler

Assistant Professor

Division of General Internal Medicine and Interdepartmental Division

of Critical Care Medicine

Sunnybrook and Women's College

Health Sciences Centre

Toronto, Ont.

\section{References}

1. Hebert PC, Wells G, Blajchman MA, Marshall J, Martin C, Pagliarello G, et al. A multicenter randomized, controlled clinical trial of transfusion requirements in critical care. Transfusion Requirements in Critical Care Investigators, Canadian Critical Care Trials Group. N Engl 7 Med 1999;340 (6):409-17.

2. Wu WC, Rathore SS, Wang Y, Radford MJ, Krumholz HM. Blood transfusion in elderly patients with acute myocardial infarction. $N$ Engl $7 \mathrm{Med}$ 2001;345:1230-6. 